\title{
Comparison of Direct Normal Irradiance Derived from Silicon and Thermopile Global Hemispherical Radiation Detectors
}

Conference Paper NREL/CP-550-48698

August 2010

\section{Preprint}

D.R. Myers

To be presented at SPIE Optics and Photonics San Diego, California August 1-5, 2010

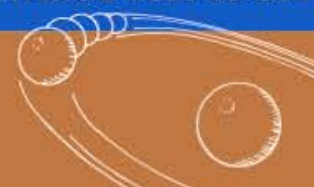




\section{NOTICE}

The submitted manuscript has been offered by an employee of the Alliance for Sustainable Energy, LLC (ASE), a contractor of the US Government under Contract No. DE-AC36-08-GO28308. Accordingly, the US Government and ASE retain a nonexclusive royalty-free license to publish or reproduce the published form of this contribution, or allow others to do so, for US Government purposes.

This report was prepared as an account of work sponsored by an agency of the United States government. Neither the United States government nor any agency thereof, nor any of their employees, makes any warranty, express or implied, or assumes any legal liability or responsibility for the accuracy, completeness, or usefulness of any information, apparatus, product, or process disclosed, or represents that its use would not infringe privately owned rights. Reference herein to any specific commercial product, process, or service by trade name, trademark, manufacturer, or otherwise does not necessarily constitute or imply its endorsement, recommendation, or favoring by the United States government or any agency thereof. The views and opinions of authors expressed herein do not necessarily state or reflect those of the United States government or any agency thereof.

Available electronically at http://www.osti.gov/bridge

Available for a processing fee to U.S. Department of Energy and its contractors, in paper, from:

U.S. Department of Energy

Office of Scientific and Technical Information

P.O. Box 62

Oak Ridge, TN 37831-0062

phone: 865.576.8401

fax: 865.576 .5728

email: mailto:reports@adonis.osti.gov

Available for sale to the public, in paper, from:

U.S. Department of Commerce

National Technical Information Service

5285 Port Royal Road

Springfield, VA 22161

phone: 800.553.6847

fax: 703.605.6900

email: orders@ntis.fedworld.gov

online ordering: http://www.ntis.gov/ordering.htm 


\title{
Comparison of direct normal irradiance derived from silicon and thermopile global hemispherical radiation detectors
}

\author{
Daryl R. Myers \\ National Renewable Energy Laboratory, 1617 Cole Blvd., Golden, CO 80401
}

\begin{abstract}
Concentrating solar applications utilize direct normal irradiance (DNI) radiation, a measurement rarely available. The solar concentrator industry has begun to deploy numerous measurement stations to prospect for suitable system deployment sites. Rotating shadowband radiometers (RSR) using silicon photodiodes as detectors are typically deployed. This paper compares direct beam estimates from RSR to a total hemispherical measuring radiometer (SPN1) multiple fast thermopiles. These detectors simultaneously measure total and diffuse radiation from which DNI can be computed. Both the SPN1 and RSR-derived DNI are compared to DNI measured with thermopile pyrheliometers. Our comparison shows that the SPN1 radiometer DNI estimated uncertainty is somewhat greater than, and on the same order as, the RSR DNI estimates for DNI magnitudes useful to concentrator technologies.
\end{abstract}

Keywords: Silicon, Thermopile, Detectors, Solar Radiation, Direct Beam, Accuracy, Uncertainty

\section{INTRODUCTION}

\subsection{Direct normal irradiance measurements}

High accuracy, high quality measurement of terrestrial direct normal irradiance (DNI) is expensive and labor intensive. Pyrheliometers are radiometers for measuring the nearly collimated beam of radiation from the solar disk, which is responsible for casting shadows. Since the solar disk subtends about $0.5^{\circ}$, the beam of DNI radiation is contained within a solid angle (cone) with an apex angle of $0.5^{\circ}$. The pyrheliometer sensors are perpendicular to the direct normal radiation beam, requiring a tracker to follow the sun and keep the sensor normal to the beam. These sensors are generally thermopile detectors in contact with black absorbing material. The absorber heats up when exposed to the solar irradiance. The thermopile generates an electrical signal proportional to the temperature difference between "cold" reference junctions at ambient temperature, and the "hot" junctions at the absorber.

To exclude sky radiation from the DNI measurement, baffles and view-limiting apertures are used to restrict the field of view of the sensors. Generally the field of view for pyrheliometers is between $5.0^{\circ}$ and $5.7^{\circ}$, or about 10 times the solar disk angular diameter. This range of fields of view was chosen when only manually adjusted or clock drive tracking mechanisms were available. It was desirable to avoid lost data by permitting relatively large $\left(1^{\circ}\right.$ to $\left.1.5^{\circ}\right)$ tracking errors to occur. From a mechanical perspective, $1 / 2$ of the $5.7^{\circ}$ cone angle $\left(2.8^{\circ}\right)$ happens to be arctangent $(\mathrm{r} / \mathrm{L})$ for a limiting aperture of radius $\mathrm{r}$ ( $=0.5$ unit) positioned at a distance $\mathrm{L}$ ( $=10$ units) from a sensor. With the view-limiting configuration prescribed, a solar tracker must follow the position of the sun in the sky with a pointing accuracy of at least $1.0^{\circ}$ in azimuth and elevation. Reducing the fields of view (down to $0.5^{\circ}$ ) would require significant reductions in tracker pointing error. It is the combination of the thermopile sensors, view limiting apertures, and tracking equipment which make pyrheliometric measurements of DNI expensive. Figure 1 shows multiple pyrheliometers mounted on a solar tracker. Mention of specific manufacturers and models of equipment does not imply any endorsement by the author, the employer of the author, or the U.S. Department of Energy. 


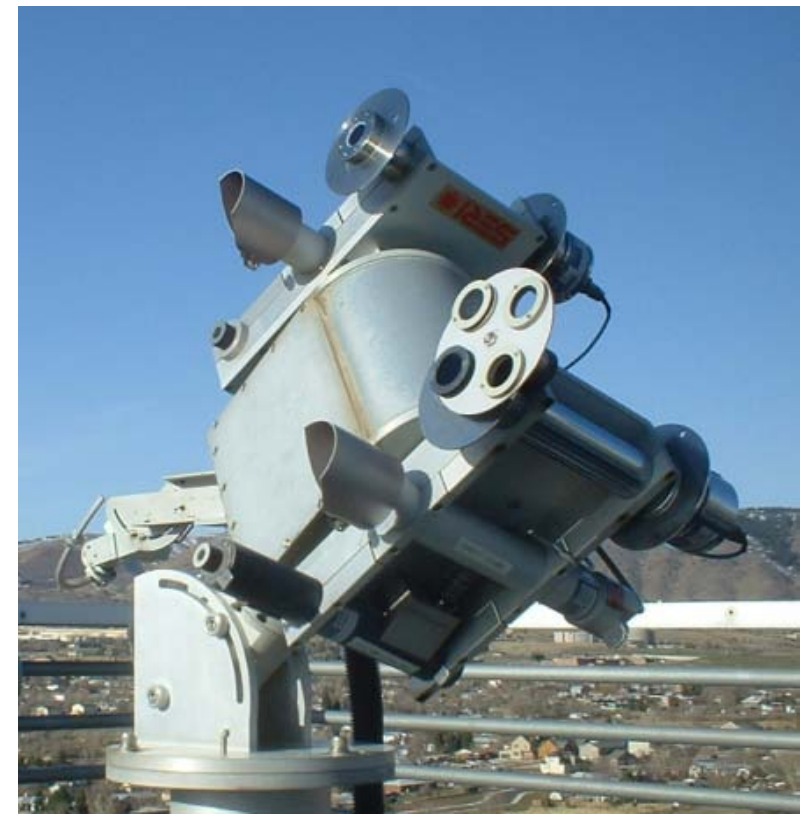

Fig. 1. Example pyrheliometers and tracker for DNI measurements (Thomas Stoffel, NREL)

\subsection{Deriving direct normal irradiance}

DNI is an element of the total hemispherical terrestrial solar radiation flux on a horizontal surface. This flux is referred to as total hemispherical solar radiation, sometimes called "global horizontal" radiation. Hemispherical radiation comprises a combination of the nearly collimated DNI and some portion of the diffuse sky radiation extracted from the beam by scattering as the DNI propagates through the atmosphere. Pyranometers are radiometers with a $180^{\circ}$ field of view that measure the total hemispherical radiation. For tilted surfaces, contributions from the sky radiation are reduced because of the "unseen" missing sky radiation, but ground-reflected radiation contributes to the hemispherical tilt radiation. In all cases, the incidence angle for the DNI on a plane is the angle between the normal to the plane and the projection of the direct beam radiation on the intercepting plane. This projection is computed from the direct DNI multiplied by the cosine of the incidence angle.

For incidence angle, $i$, DNI magnitude, $B$, diffuse sky radiation value, $F$, and possibly ground-reflected radiation, $R$, a pyranometer measures global horizontal irradiance $G=B \cos (i)+F+R$. For the purposes of this paper, we are interested in DNI radiation, where the surface is normal to the direct beam, the incidence angle $i$ is zero, and the ground-reflected and diffuse sky contributions are zero.

Several types of detectors are the basis of commercial pyranometers. These include thermopiles and silicon diode solidstate detectors. Thermopile detectors are generally protected under glass or quartz domes. The combination of wideband thermopile detector response and typical spectral transmission of the protective domes allow these pyranometers to respond to radiation from 280 nanometers $(\mathrm{nm})$ to $2,800 \mathrm{~nm}$. Silicon detectors respond only to the 300 $\mathrm{nm}$ to $1,100 \mathrm{~nm}$ spectral region of the solar spectrum, as shown in Figure 2. The ability of each detector to respond over these spectral ranges means the accuracy of data obtained from each will be different ${ }^{1}$. We address the relative accuracy of time integrated, summed, or averaged solar radiation data as measured by both thermopile and silicon cell types of detectors. Figure 3 shows examples of thermopile and silicon pyranometers.

Knowledge of the global (total) horizontal irradiance $G$, diffuse sky irradiance $F$, and zenith angle $Z$ (complement of the solar elevation angle) with respect to a horizontal detector allows one to derive DNI: $B=(G-F) / \cos (Z)$. This is the principle upon which the rotating shadowband radiometer operates. An unshaded, horizontal radiometer (usually a silicon pyranometer) measures $G$. Periodically a band (designed to shade only the solar disk) rotates in position to allow the pyranometer to measure $F$. See Figure 4 . A similar but static approach is to measure $G$ and $F$ from a complement of 
identical, simultaneously shaded and unshaded (thermopile) sensors under a specially designed mask (the Delta-T SPN1 sunshine pyranometer), also shown in Figure 4.

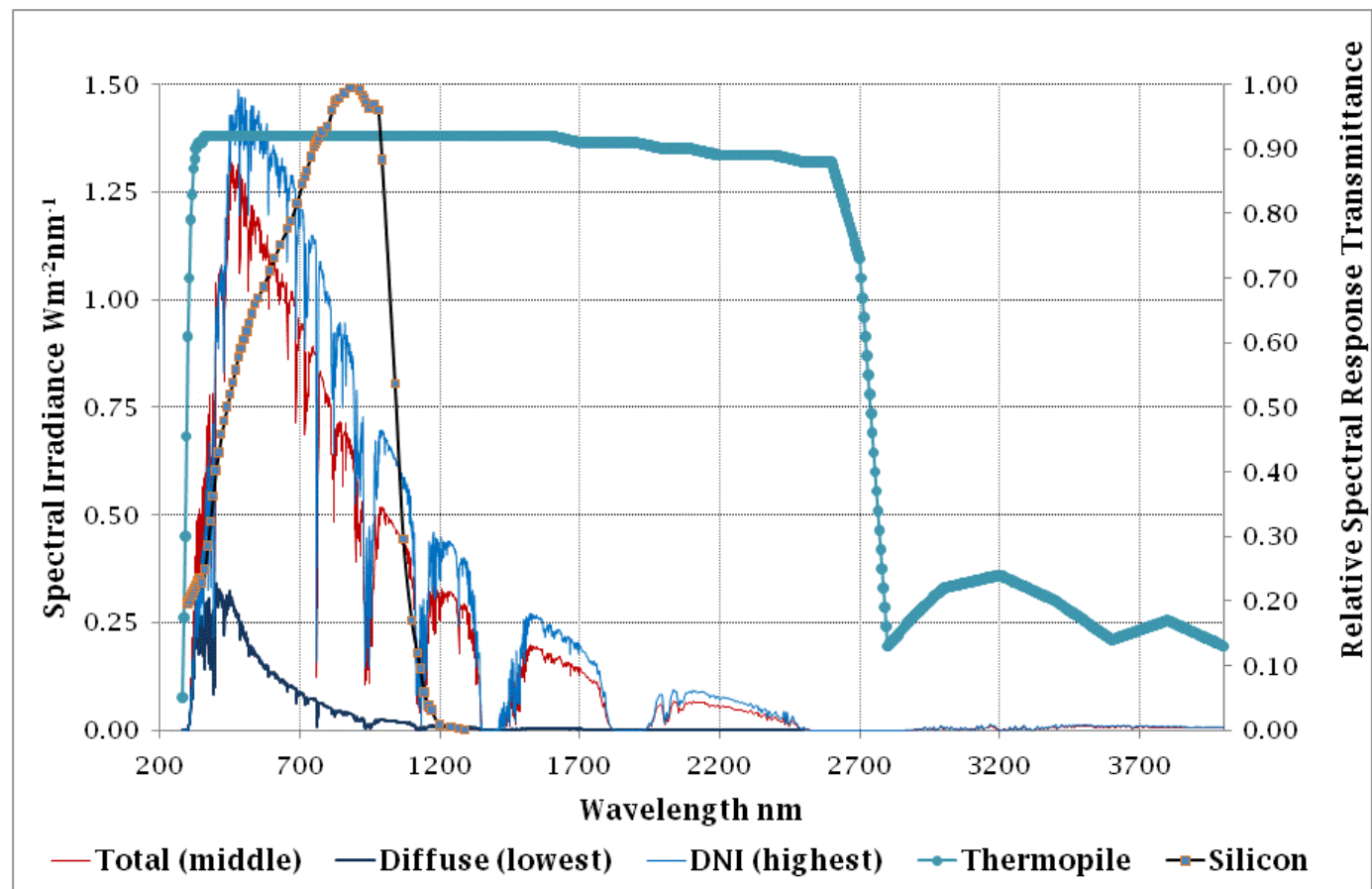

Fig. 2. Example DNI, total global hemispherical irradiance, and diffuse hemispherical solar spectra on a horizontal surface, with typical pyrheliometer/pyranometer thermopile and silicon radiometer response functions.
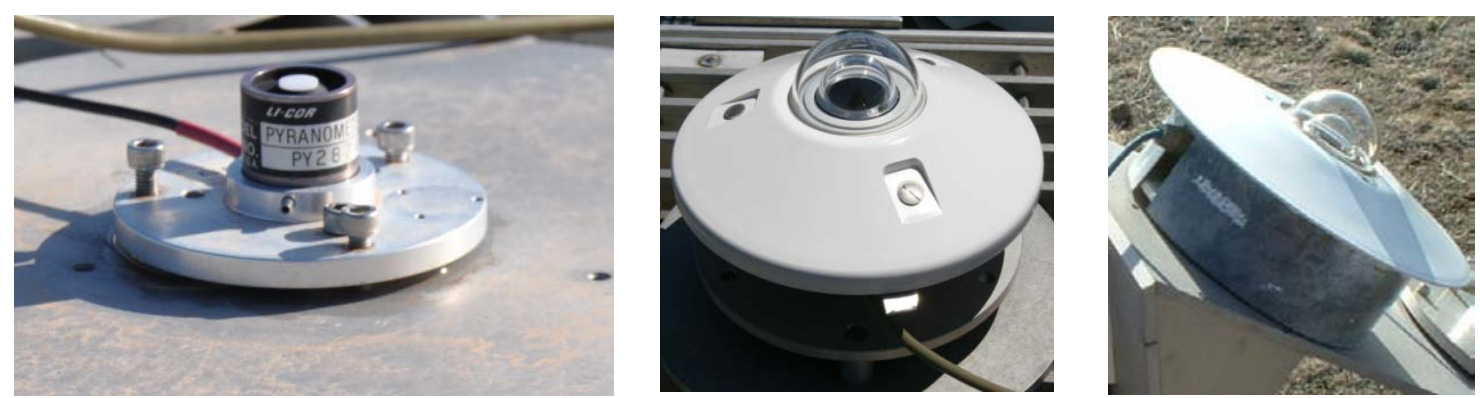

Fig. 3. Examples of silicon detector (left) and thermopile detector pyranometers for measuring total hemispherical solar radiation on a horizontal or tilted surface (Thomas Stoffel, NREL)

\section{SOLAR RADIATION CALIBRATION}

\subsection{Solar radiometer calibration reference: the Word Radiometric Reference}

The internationally accepted traceable reference for the measurement of terrestrial solar radiation is the World Radiation Reference (WRR) maintained by a group of absolute cavity pyrheliometers (devices to measure the direct beam irradiance) at the World Radiation Center (WRC) at the Physical Meteorological Observatory, Davos, Switzerland ${ }^{2}$. The present accepted inherent uncertainty in the WRR is $\pm 0.30 \%$. . Reference absolute cavity pyrheliometers ${ }^{4,5}$ used as national and institutional standards are calibrated against the WRR at "International Pyrheliometric Comparisons" every five years at WRC. Transfer of calibration from WRR to national or working standard absolute pyrheliometers results in uncertainty in these standards of about $\pm 0.45 \%{ }^{6}$. 

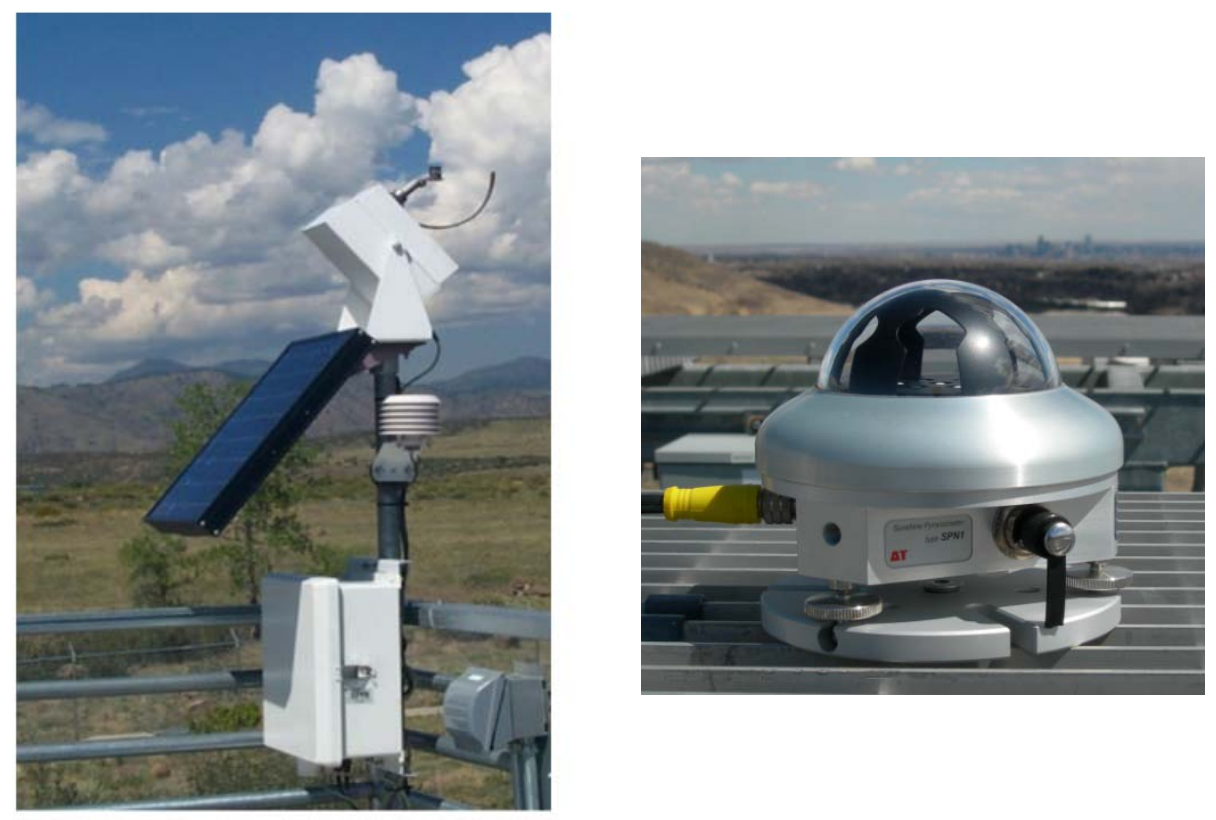

Fig. 4. Two means of measuring global and diffuse radiation with single instrument. Rotating shadowband radiometer (RSR, left) with silicon pyranometer, and global/diffuse hemispherical measuring SPN1 pyranometer with multiple fast thermopiles (right) under specially designed shading mask (Thomas Stoffel, NREL).

\subsection{Radiometer calibration}

The WRR is the reference for calibration of pyrheliometers and pyranometers. Pyrheliometers are compared directly against reference pyrheliometers, typically WRR traceable working standard absolute cavity pyrheliometers. Clear sky signals from test pyrheliometers are divided into reference DNI from a cavity pyrheliometer over an appropriate period (usually an entire day), and averaged [over a specified zenith angle range; the National Renewable Energy Laboratory (NREL) typically uses $\mathrm{Z}=45^{\circ} \pm 0.2^{\circ}$ ] to produce a calibration factor, $\mathrm{Cf}$ (watts per square meter per millivolt, $\mathrm{W} / \mathrm{m}^{2} / \mathrm{mV}$ ). The reciprocal of the calibration factor is the radiometer responsivity (Rs) (volts per watt per square meter, $\mathrm{V} / \mathrm{W} / \mathrm{m}^{2}$ ). Uncertainty in the pyrheliometer $\mathrm{Cf}$ and Rs calibrations referenced to absolute cavity pyrheliometers is $\pm 1.0 \%$. Field measurements for pyrheliometers are typically uncertain to $\pm 2.0 \%$.

For pyranometers, horizontal sensors respond only to the vertical component of the direct beam, $B \cdot \cos (Z)$, and not to the horizontal component, $B \cdot \sin (\mathrm{Z})$. By shading and unshading a horizontal sensor on a clear day, the difference in signal between shaded and unshaded conditions, in combination with the direct beam measurement and the zenith angle, can be used to determine the pyranometer Cf. A cavity pyrheliometer and a continuously shaded pyranometer (calibrated using the shade/unshade technique) may be used to compute a hemispherical reference total hemispherical irradiance. Dividing the reference irradiance by the test pyranometer signal produces the pyranometer $\mathrm{Cf}$. This is called the "component summation" calibration technique 5

Conducted over a range of zenith angles, both shade/unshade and component summation techniques reveal that both pyranometers and pyrheliometers (to a lesser extent) have non-constant response as a function of the zenith angle. These differences in radiometer response as function of zenith angles are "fingerprints" or "signatures" for each individual (not just type) radiometer. The variations can be symmetrical with respect to solar noon, or highly variable. These variations depend on the mechanical structure of the radiometer sensor, sensor surface, absorber material properties, etc. Figure 5 shows examples of responsivity as a function of zenith angle, the mean Rs at $Z=45^{\circ}$, and error bars on mean Rs, for example, thermopile and silicon detector pyranometers and a pyrheliometer. 


\subsection{Calibration and measurement uncertainty}

Typical calibration uncertainty for any sensor with respect to a WRR reference cavity radiometer is about $0.5 \%$ at any one very narrow range $\left( \pm 2^{\circ}\right.$ to $\left.\pm 5^{\circ}\right)$ of zenith angle 6 . Over a wide range of zenith angles $\left(0^{\circ}\right.$ to $\left.85^{\circ}\right)$, some pyranometer calibration factors can vary by 10 to 20 times that over a narrow range, or from $\pm 3 \%$ to $\pm 10 \%$ or even more. In most applications, a single calibration factor for converting the radiometer signal in volts to irradiance engineering units is needed. Since the average "zenith angle" for an isotropic sky is $45^{\circ}$, NREL reports the responsivity or calibration factor resulting from outdoor calibrations for the zenith angle range of $45^{\circ} \pm 0.2^{\circ}{ }^{6}$. This also provides a means of comparison with the manufacturer's calibrations derived using integrating spheres or hemispheres and isotropic artificial illumination ${ }^{7}$. These effects then need to be combined with the field measurement influences, such as data logger accuracy, cleanliness, temperature and other environmental influences, to produce (higher, never lower) field measurement uncertainty. Note that high zenith-angle-related uncertainties occur when the available solar resource is lower than "midday" resources. Since the maximum elevation (minimum zenith) angles vary through the seasons, the uncertainty in pyranometer radiation data will vary as well.

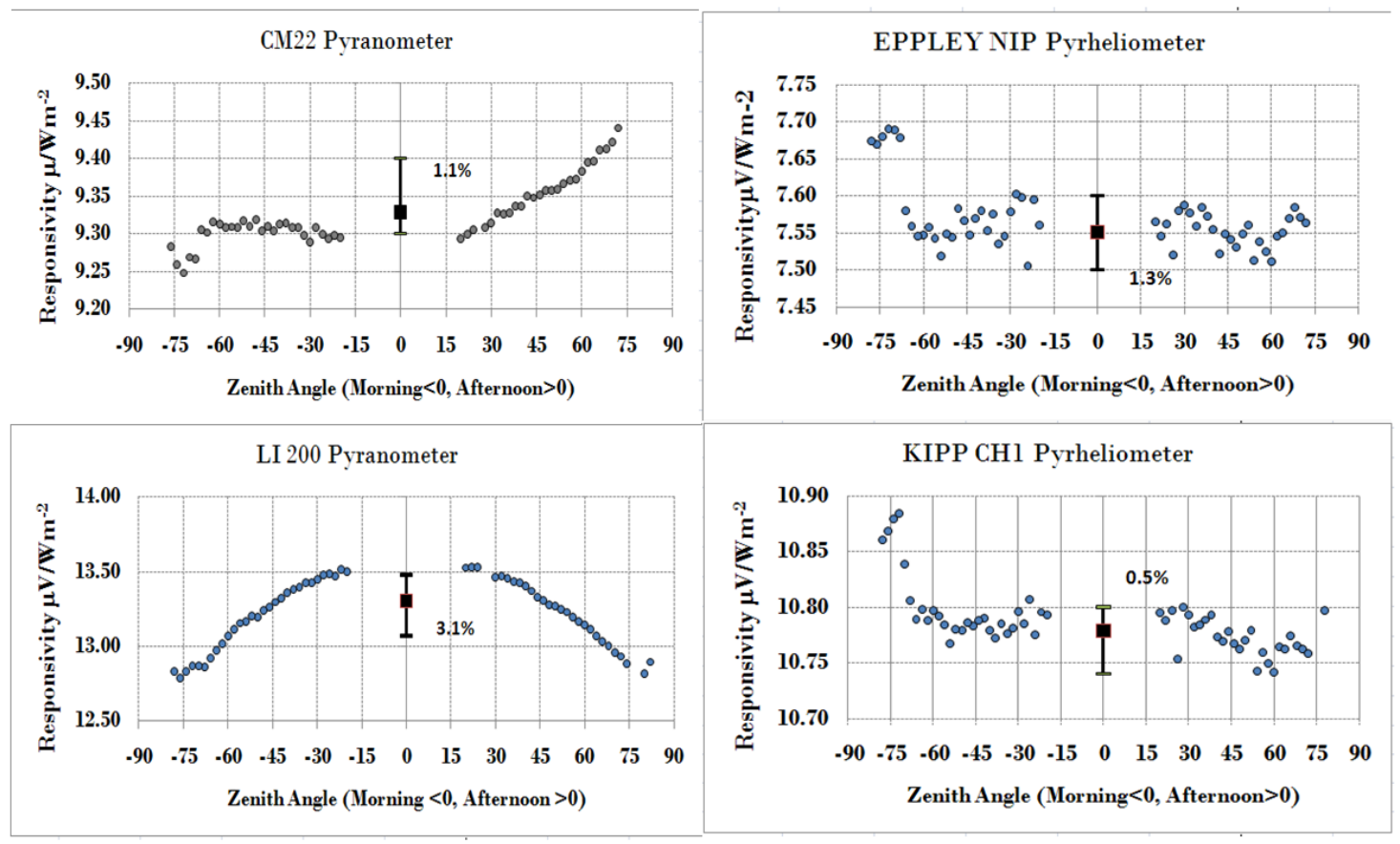

Fig. 5. Responsivity, Rs, as a function of zenith angle for silicon detector (LiCor LI-200), thermopile detector pyranometer (Kipp \& Zonen CM22), and two thermopile pyrheliometers (NIP, CH1). Pyranometer responses derived from component summation technique, pyrheliometers compared directly with reference absolute cavity radiometer. Zenith angles shown as $<0$ for morning, and $>0$ for afternoon. Gap is where zenith angles not achieved at NREL due to location (39 deg N Latitude), Black squares at $Z=0$ are mean Rs at $Z=45^{\circ}$. Error bars about Rs at $45^{\circ} \mathrm{Z}$ apply to $30^{\circ}<Z<60^{\circ}$

If a user applies only the single "average" responsivity reported for a radiometer, the variations in responsivity shown in Figure 5 mean that errors in radiometric data are distributed across the day. Using the LiCor LI-200 response curve (lower left of Figure 5) as an example, for the same signal level, in millivolts, data reported near noon are high, and data in the mornings and afternoon are too low with respect to more accurate calibration factor or responsivity for those periods of the day. These examples represent an absolute error of $+1.7 \%$ to $-1.7 \%$, or a $3.4 \%$ range. The range of possible error for the pyrheliometer data is much less, typically around $1.0 \%$ for the calibrations, as seen above. The rest of this paper examines the relative accuracy of thermopile and silicon-based pyranometers "on average" over periods of 1 minute and hourly averages, using such "average" calibration factors. All radiometers in this study except the SPN1 units are calibrated annually, traceable to the WRR, using the component summation technique, with average uncertainty within individual $2^{\circ}$ wide zenith angle bins of $0.5 \%$ on each responsivity data point. The manufacturer's calibration of the SPN1 units is described below. 
We compare the DNI radiation computed from an Irradiance, Inc., RSR model 2 (RSR2), a Delta-T SPN1 pyranometer mounted horizontally, a second SPN1 mounted at latitude $\left(40^{\circ}\right)$ tilt to the south, and a thermopile pyrheliometer (Kipp $\&$ Zonen model CH1). The SPN1 radiometer design is detailed in Wood, Muneer, and Kubie ${ }^{8}$.

SPN1 calibration is dependent upon the multiple thermopiles having the same response to the same signal for the same stimulus. The individual signals are "trimmed" to match under uniform illumination from an exit port of a 12-inch integrating sphere illuminated with an artificial source approximately matching the intensity and spectral distribution of sunlight ${ }^{9}$. The mask is designed to mask $50 \%$ of the sky dome for both the shaded and unshaded sensors. The manufacturer supplies a cosine response curve, as shown in Figure 6 (adapted from "User Manual for the Sunshine Pyranometer type SPN1" $)$. Figure 7 shows an experimentally derived relative cosine response for the horizontal SPN1 derived by dividing the SPN1 global hemispherical data by the CM22 global hemispherical data. The spread in the relative response data in Figure 7 may be due to different time constants for the two radiometers.

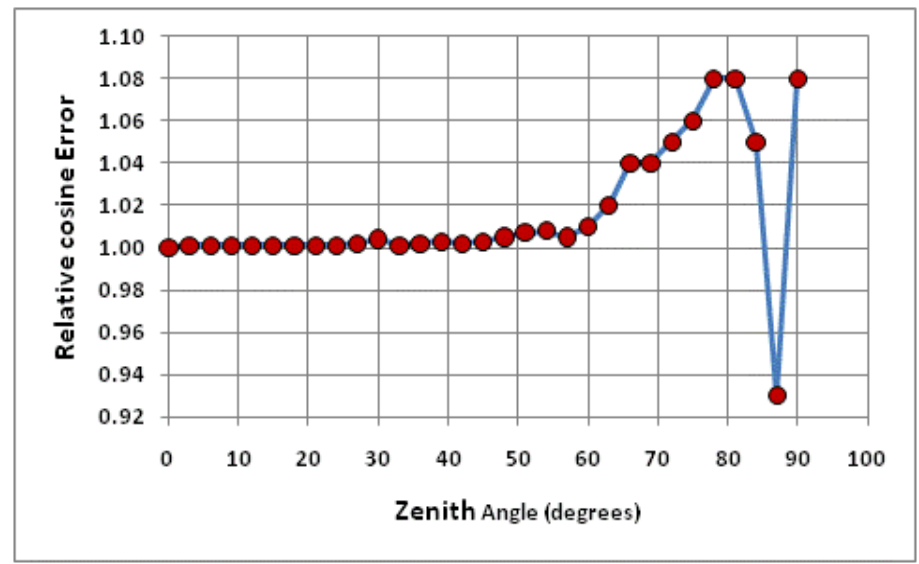

Fig. 6. SPN1 cosine reponse error as reported by the manufacturer.

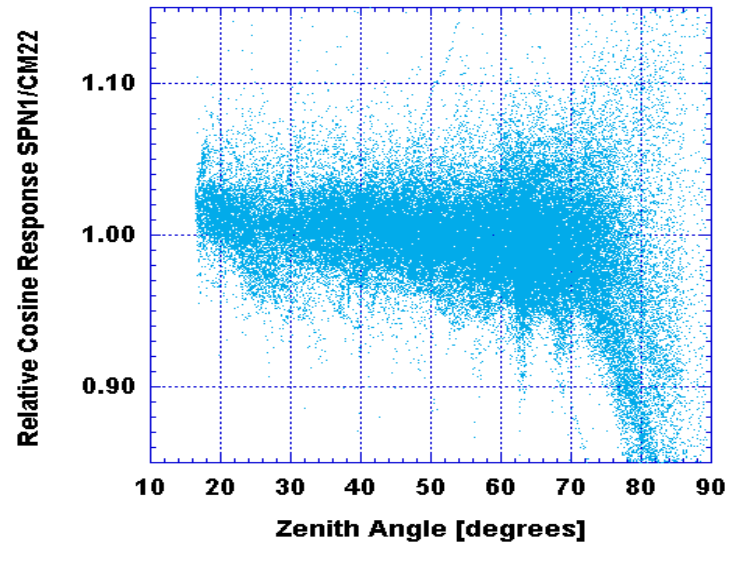

Fig. 7. Experimentally derived cosine response error for SPN1 relative to the CM22 thermopile pyranometer

For comparison purposes, the relative cosine response of the corrected RSR with respect to the same CM22 radiometer is shown in Figure 8. These results imply that relative cosine response differences between these two pyranometers can amount to about $\pm 5 \%$ over the range of zenith angles from $20^{\circ}$ to $60^{\circ}$ for the SPN1 and $+8 \%$ to $-3 \%$ for the RSR silicon pyranometer.

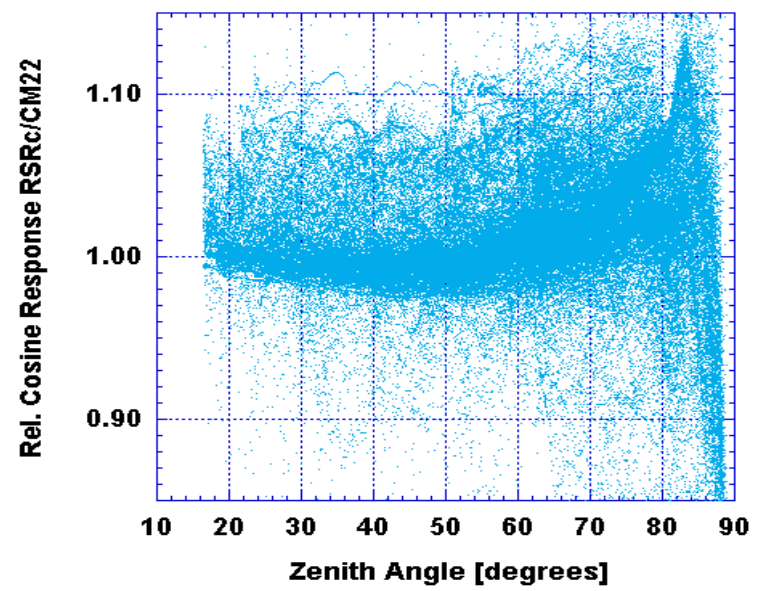

Fig. 8. Relative cosine response as a function of zenith angle of corrected RSR. Ratio computed from RSR2 corrected global hemispherical data divided by CM22 global hemispherical data. 
Our reference pyrheliometer has a measurement uncertainty of about $\pm 2 \%$. The derived DNIs from the SPN1 and RSR contain a combination of uncertainty in cosine response for the global hemispherical and the diffuse data. We estimate that the diffuse data contributes on average $30 \%$ of the error in the DNI calculation. The combined DNI and pyranometer cosine response-related errors are combined using the root sum square for estimated DNI uncertainty as follows:

For the SPN1: $\left[(0.05)^{2}+(0.05 * 0.3)^{2}+(0.02)^{2}\right]^{0.5}=0.054$, or $\pm 5.4 \%$

For the RSR2: $\left[(0.08)^{2}+(0.08 * 0.3)^{2}+(0.02)^{2}\right]^{0.5}=0.083$, or $\pm 8.3 \%$

We expect differences between the estimated DNI and the reference DNI larger than 5\% to $8 \%$ to result from other causes. In addition to the differing zenith angle dependent errors shown in Figure 5, differences in high time resolution data are apparent. The time constants for silicon detectors are on the order of milliseconds, while the thermopile (and reference irradiance) sensors have time constants on the order of 1 to 3 seconds. The SPN1 pyranometer thermopiles are specified as having an intermediate time constant of about 0.5 seconds. Thus, under highly variable (passing cloud) conditions, large differences can arise from the discrepancy in the ability of the sensors to follow the rising and falling irradiance values on a 3 -second sample rate basis. The fast responding silicon radiometer may track changing irradiances "better" than the slower (thermopile based) reference irradiance. The performance of the faster RSR2 silicon pyranometer and SPN1 fast thermopiles contributes to some of the differences, or "error," with respect to the slower responding $\mathrm{CH} 1$ pyrheliometer thermopile. We would expect averaging over longer periods (such as an hour) would reduce the impact of this effect.

\section{DATA COLLECTION AND PROCESSING}

\subsection{Data collection}

The data analyzed here was collected from December 2009 to June 2010 at the NREL Solar Radiation Research Laboratory (SRRL), which is located at $39.74 \mathrm{~N}, 105.08 \mathrm{~W}$, at an elevation of 1,820 meters $(6,000 \mathrm{ft})$ near Golden, Colorado. The radiometers are components of the SRRL Baseline Measurement System (BMS), which comprises numerous solar radiation and meteorological sensors. All of the data are publically accessible through the Measurements and Instrumentation Data Center (MIDC) maintained at SRRL (see http://www.nrel.gov/midc/srrl_bms). All sensors are sampled every 3 seconds, and 1-minute averages of the sampled data are computed and archived. The data from the four different radiometer configurations at the 1-minute and hourly average sample periods are compared below.

\subsection{One-minute DNI data comparisons}

We calculated the percent differences between the $\mathrm{CH} 1$ reference pyrheliometer DNI and the following DNIs using the formula: $100 *[(\mathrm{CH} 1-\mathrm{Test}) / \mathrm{CH} 1]$ :

- RSR2u "uncorrected" DNI computed from uncorrected global horizontal, GH, diffuse horizontal, FH, and $\cos (Z)$

- $\quad$ RSR2c "corrected" DNI computed by applying spectral corrections (with respect to air mass) to GH and FH

- SPN1 DNI computed from a radiometer measuring GH and FH, and the zenith angle

- SPN1 DNI computed from a radiometer mounted at latitude $40^{\circ}$ tilt, measuring hemispherical, GT, and diffuse hemispherical, FT, radiation, and the cosine of the incidence angle of the direct beam on the tilted surface.

The data were filtered to include only DNI values above $10 \mathrm{~W} / \mathrm{m}^{2}$ to avoid large ratios of small numbers.

Figure 9 shows the percentage "error" of difference in the 1-minute data points as a function of the magnitude of the reference DNI. 

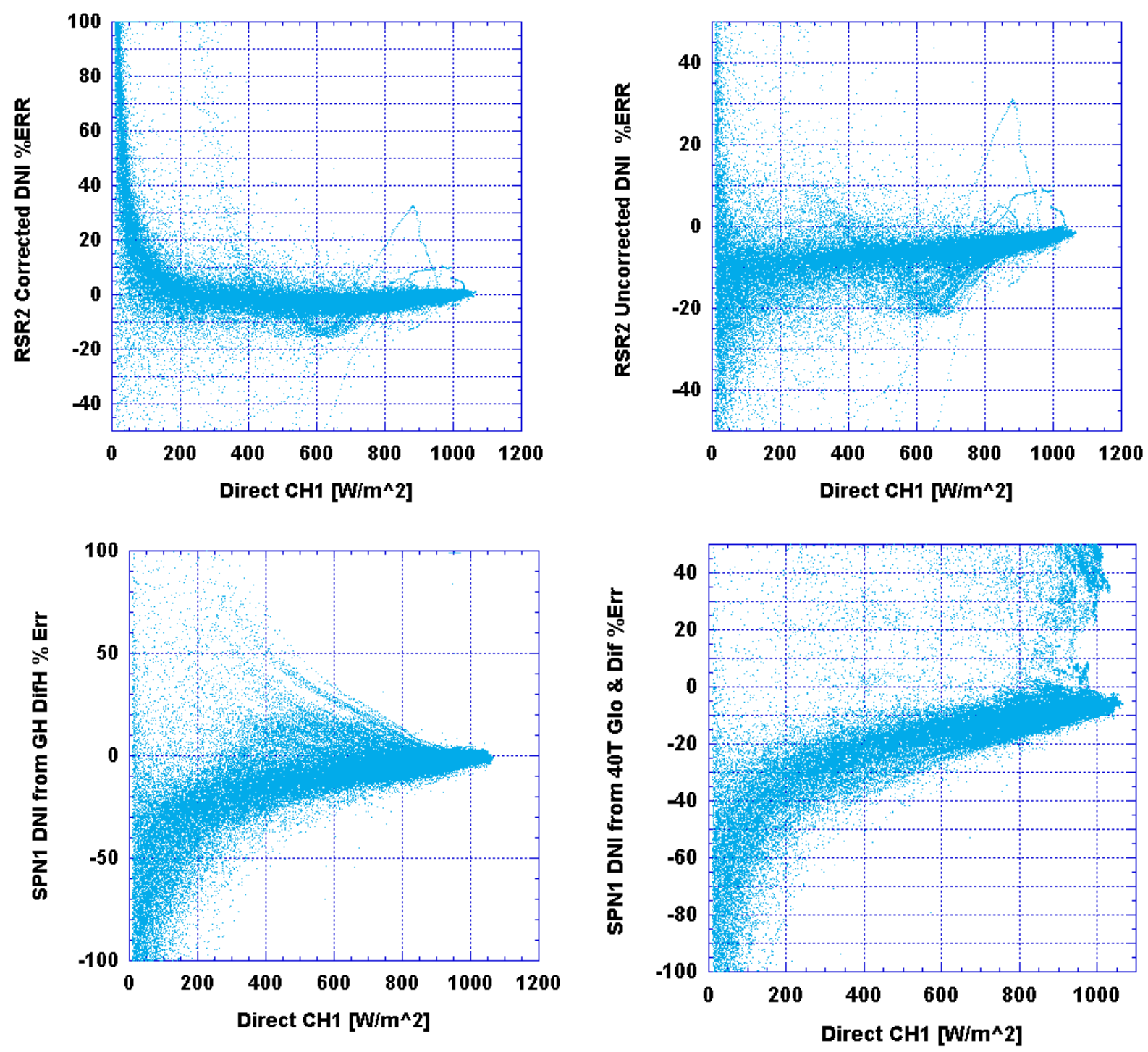

Fig. 9. Plots of percent difference, or "error," as a function of DNI between reference CH1 DNI and DNI derived from corrected (top left) and uncorrected (top right) RSR2 global and diffuse hemispherical irradiance, and horizontal (bottom left) and $40^{\circ}$ tilted (bottom right) SPN1 global and diffuse measurements, using the appropriate incidence angle.

It is apparent from Figure 9 that for DNI less than $800 \mathrm{Wm}^{-2}$, the SPN1-derived DNI show significantly greater error than the approximately 5\% window from our uncertainty analysis. The RSR2 distribution of differences is much tighter for both the corrected and uncorrected computations, on the order of $\pm 10 \%$ for DNIs greater than about $300 \mathrm{Wm}^{-2}$.

The SPN1 differences above the $800 \mathrm{Wm}^{-2}$ level, within $\pm 10 \%$, appear to be reasonable. The larger differences at lower DNI values may be due to the geometrical effect of the shading mask, especially with respect to the measurement of the diffuse sky radiation and the relative position of the direct beam at high zenith angles. Though the "unshaded" and "shaded" thermopiles in the SPN1 design both "see" some portion of the sky blocked by the mask, the relative impact of the direct beam on the shape and sharpness of the shadows cast may affect the diffuse and global measurements. The "cloud" of large differences (above $20 \%$ ) between $800 \mathrm{Wm}^{-2}$ and $1,000 \mathrm{Wm}^{-2}$ in the latitude $40^{\circ}$ tilt SPN1 plot are due to signal cabling problems and connections to the data logger, resulting in a large increase in the noise-to-signal ratio in early June. 
The densest part of the SPN1 cloud of points in the error plots is on the order of $15 \%$ wide, and the increasing magnitude of the errors at low DNI irradiances suggests a strong dependence of the DNI on zenith angle, or incidence angle, since DNI decreases rapidly at a high zenith angle. In addition, other causes of low DNI signal, such as persistent, thin clouds, as well as the aforementioned time constant response differences under highly transient conditions, may contribute to these larger errors. The slope of the error curve for the horizontal SPN1 radiometer flattens out earlier (bottom left of Figure 9) than that of the latitude tilt SPN1 error curve (bottom right of Figure 9). This may be because the relative contribution of the diffuse irradiance to the total hemispherical for the horizontal radiometer is greater than for the tilted SPN1, which sees less diffuse sky (though some ground reflected radiation makes up for some of the lost sky radiation). That is, errors in the tilted SPN1-derived DNI may be sensitive to the ground albedo, and relative strength of the (tilted) total hemispherical irradiance with respect to the (tilted) diffuse hemispherical irradiance. Finally, the consistent shape of the difference, or "error" curves seen here imply that some correction function based on DNI magnitude might be developed and applied to the derived SPN1 data, and provide estimated DNI values with an uncertainty on the order of $\pm 15 \%$, versus $\pm 10 \%$ for the RSR estimates.

\subsection{Hourly DNI data comparisons}

To see if the relative differences between the reference CH1 pyrheliometer DNI and the SPN1 and RSR DNI estimates can be reduced by averaging, we computed the hourly average DNI for each of the four radiometers. The results are shown in Figure 10.
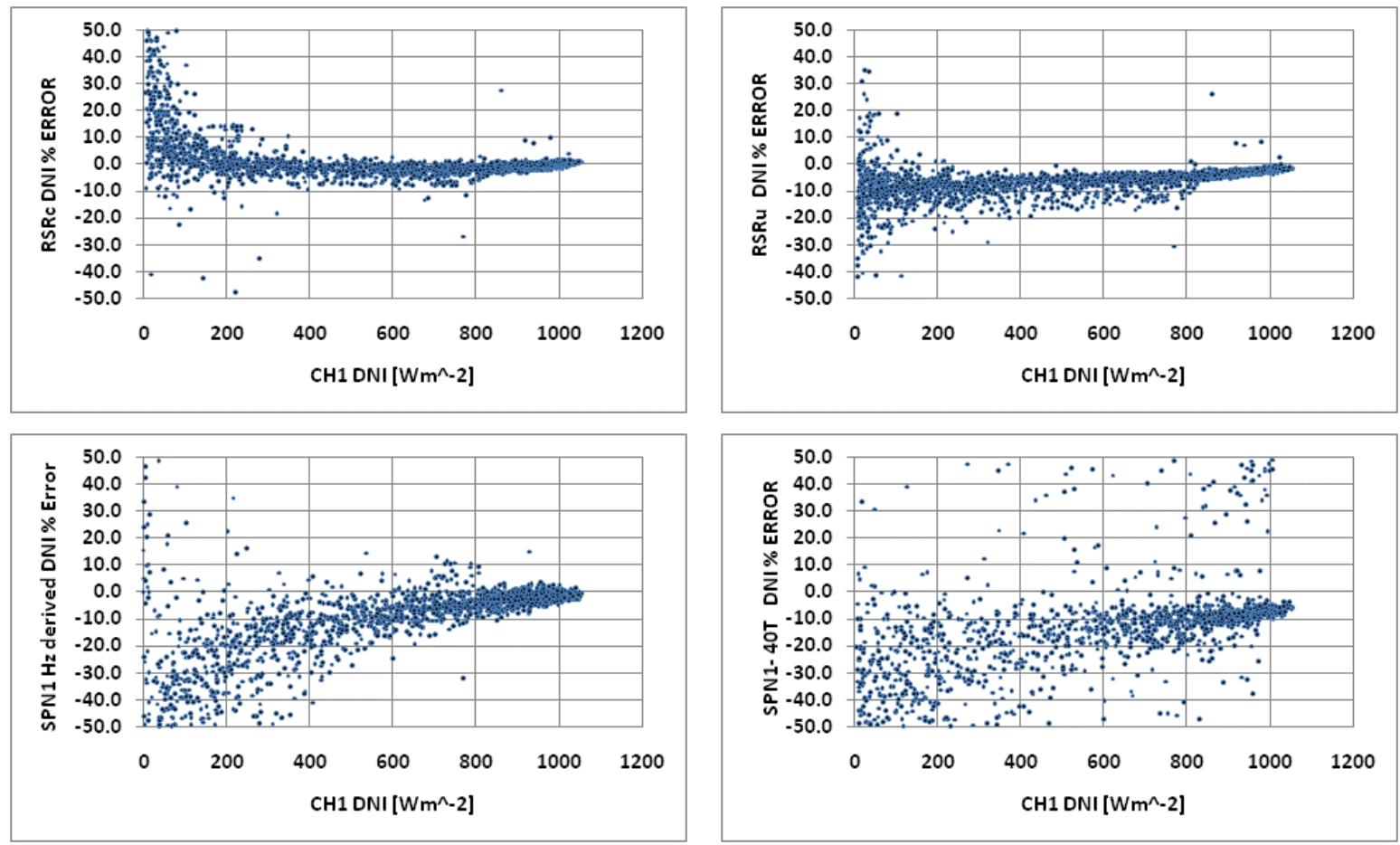

Fig. 10. Relative percent error in estimated DNI with respect to $\mathrm{CH} 1$ reference DNI for hourly averaged data from corrected (top left), uncorrected (top right) RSR and horizontal (bottom left) and $40^{\circ}$ tilted SPN1 radiometers.

As expected, averaging over a longer period reduces the scatter in the relative error plots for the estimated DNI. The RSR units still perform better than the SPN1, having a much narrower range of error, less than $\pm 5 \%$ for the corrected RSR2 data above $400 \mathrm{Wm}^{-2}$ DNI. The SPN1 range of DNI differences is still about $\pm 10 \%$ to $\pm 15 \%$, or two to three times the RSR2 range. It appears the horizontal deployment of the SPN1 instrument is preferable to a tilted deployment, perhaps because of the influence of ground albedo on the tilted hemispherical diffuse data. However, for DNI magnitudes above $600 \mathrm{Wm}^{-2}$, the horizontal SPN1 hourly averages are within about $10 \%$ of the reference CH1 data. This suggests that the horizontal SPN1 radiometer can be used to estimate DNI in locations with high DNI resources with somewhat larger (about 50\% more) uncertainty than estimates derived from the RSR2 radiometer. 


\section{SUMMARY AND CONCLUSIONS}

We analyzed 6 months of 1-minute and hourly averaged DNI estimates from two radiometer systems with respect to a reference pyrheliometric measurement of direct beam. The data were collected simultaneously by both thermopile and silicon-based detector types of radiometers at the NREL SRRL. The Irradiance, Inc., RSR and Delta-T SPN1 Sunshine pyranometer both measure total hemispherical and diffuse hemispherical radiation and can be used to derive the direct radiation from those parameters and the computed incidence angle of the direct beam. The RSR data can be corrected for spectral and temperature effects, so both the corrected and uncorrected data were analyzed. The SPN1 radiometer can be mounted in any orientation, so horizontal and latitude tilt orientations were evaluated using two different instruments. The calibration and measurement uncertainty analysis based on experimental determination of relative cosine response errors, in combination with the uncertainty in the reference pyrheliometer resulted in expected differences in the SPN1 and RSR2 estimates of DNI in the range of 5\% and 8\%, respectively. The RSR-based estimates generally were as good as or better than the expected $\pm 8 \%$ uncertainty window for the 1-minute average and hourly average data. The SPN1 radiometers produced DNI estimates with larger ranges of error, three to four times the expected uncertainty window, or $\pm 15 \%$ to $20 \%$, especially at DNIs below $400 \mathrm{Wm}^{-2}$. At higher DNIs, above $600 \mathrm{wm}^{-2}$, which is useful for concentrating solar applications, the SPN1 horizontal radiometers produces DNI estimates with uncertainty comparable to the RSR2 DNI estimates $( \pm 10 \%)$ for both 1 minute and hourly averaged data.

\section{ACKNOWLEDGEMENTS}

Special thanks to Beverly Kay, Peter Gotseff, and Afshin Andreas for their untiring efforts to maintain the NREL/SRRL/MIDC website and quality radiometer calibrations and solar radiation data. This work was performed under Prime Contract No. DE-AC36-08GO28308, between the Alliance for Sustainable Energy, LLC, and the U.S. Department of Energy.

\section{REFERENCES}

[1] Alados-Arboledas, L., Batlles, F.J., and Olmos, F.J., "Solar Radiation Resource Assessment by Means of Silicon Cells," Solar Energy 54(3) 183-191 (1995).

[2] World Meteorological Organization OMM No. 8 Guide to meteorological instruments and methods of observation. Secretariat of the World Meteorological Organization, Geneva, 7th ed. (2008).

[3] Frohlich, C., "History of solar radiometry and the World Radiation Reference," Metrologia 28 111-115 (1991).

[4] Reda, I., Stoffel, T., Myers, D., Calibration of a solar absolute cavity radiometer with traceability to the World Radiometric Reference. NREL/TP-463-20619, National Renewable Energy Laboratory, Golden, Colorado. (1996). http://www.nrel.gov/docs/legosti/fy96/20619.pdf

[5] ASTM G167-05 "Standard test method for calibration of a pyranometer using a pyrheliometer." ASTM International, West Conshohocken, Pennsylvania (2005).

[6] Reda, I., Myers, D., and Stoffel, T., "Uncertainty Estimate for the Outdoor Calibration of Solar Pyranometers: A Metrologist's Perspective," Journal of Measurement Science 3(4) 58-66 (2008).

[7] Drummond, A.J., "Standardized Procedures in the North American Continent for the Calibration of Solar Radiation Pyranometers," Solar Energy 10(4) 184-187 (1966).

[8] Wood, J., Muneer, T., and Kubie, J., "Evaluation of a New Photodiode Sensor for Measuring Global and Diffuse Irradiance and Sunshine Duration," Journal of Solar Energy Engineering $12543-47$ (2003).

[9] Anon. "User Manual for the Sunshine Pyranometer type SPN1," Delta-T Devices Ltd. (2007). 


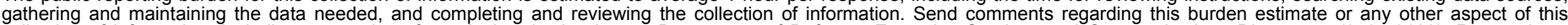

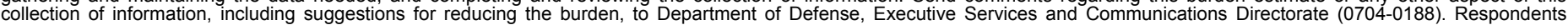

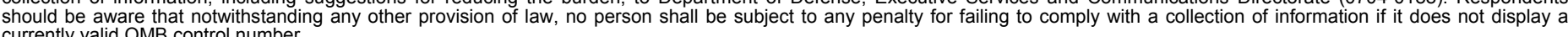

PLEASE DO NOT RETURN YOUR FORM TO THE ABOVE ORGANIZATION.
1. REPORT DATE (DD-MM-YYYY) August 2010
4. TITLE AND SUBTITLE
Comparison of Direct Normal Irradiance Derived from Silicon and
Thermopile Global Hemispherical Radiation Detectors: Preprint

3. DATES COVERED (From - To)

5a. CONTRACT NUMBER

DE-AC36-08-GO28308

5b. GRANT NUMBER

5c. PROGRAM ELEMENT NUMBER

5d. PROJECT NUMBER

NREL/CP-550-48698

5e. TASK NUMBER

SS10.1510

5f. WORK UNIT NUMBER
7. PERFORMING ORGANIZATION NAME(S) AND ADDRESS(ES)

National Renewable Energy Laboratory

1617 Cole Blvd.

Golden, CO 80401-3393

9. SPONSORING/MONITORING AGENCY NAME(S) AND ADDRESS(ES)

\section{PERFORMING ORGANIZATION REPORT NUMBER \\ NREL/CP-550-48698}

10. SPONSOR/MONITOR'S ACRONYM(S) NREL

11. SPONSORING/MONITORING AGENCY REPORT NUMBER

12. DISTRIBUTION AVAILABILITY STATEMENT

National Technical Information Service

U.S. Department of Commerce

5285 Port Royal Road

Springfield, VA 22161

13. SUPPLEMENTARY NOTES

14. ABSTRACT (Maximum 200 Words)

Concentrating solar applications utilize direct normal irradiance (DNI) radiation, a measurement rarely available. The solar concentrator industry has begun to deploy numerous measurement stations to prospect for suitable system deployment sites. Rotating shadowband radiometers (RSR) using silicon photodiodes as detectors are typically deployed. This paper compares direct beam estimates from RSR to a total hemispherical measuring radiometer (SPN1) multiple fast thermopiles. These detectors simultaneously measure total and diffuse radiation from which DNI can be computed. Both the SPN1 and RSR-derived DNI are compared to DNI measured with thermopile pyrheliometers. Our comparison shows that the SPN1 radiometer DNI estimated uncertainty is somewhat greater than, and on the same order as, the RSR DNI estimates for DNI magnitudes useful to concentrator technologies.

15. SUBJECT TERMS

Silicon; Thermopile; Detectors; Solar Radiation; Direct Beam; Accuracy; Uncertainty

\begin{tabular}{|c|c|c|}
\hline $\begin{array}{l}\text { a. REPORT } \\
\text { Unclassified }\end{array}$ & $\begin{array}{l}\text { b. ABSTRACT } \\
\text { Unclassified }\end{array}$ & $\begin{array}{l}\text { c. THIS PAGE } \\
\text { Unclassified }\end{array}$ \\
\hline
\end{tabular}

\begin{tabular}{l|l|}
$\begin{array}{l}\text { 17. LIMITATION } \\
\text { OF ABSTRACT }\end{array}$ & $\begin{array}{l}\text { 18. } \\
\text { NUMBER } \\
\text { OF PAGES }\end{array}$ \\
UL & \\
\end{tabular}

19a. NAME OF RESPONSIBLE PERSON

19b. TELEPHONE NUMBER (Include area code) 